\title{
The sustainable development training strategy of school-enterprise cooperation with excellent plan service for the national Marine development strategy
}

\author{
Jing $\mathrm{Xu}^{1}$, Bin $\mathrm{Li}^{1}$, Kun Qian ${ }^{1}$, Limei Feng ${ }^{1}$, Jun Sun ${ }^{1,{ }^{*}, \mathrm{a}}$ \\ ${ }^{1}$ Department of Mechanical Engineering, Hangzhou Dianzi University, Hangzhou, 310018, China. \\ ahdujixie2108@163.com
}

Keywords: Marine development strategy, excellent plan, school-enterprise cooperation, train

\begin{abstract}
In this paper, around the new demand of national Marine development strategy, with the intent to train excellence engineers and to find the common interest and cooperation, then improve the initiatives and effectiveness of which the enterprises cooperate with universities. Based on the traditional personnel training mode, established a set of feasible school-enterprise cooperation excellent mechanical engineer sustainable development training strategy. Finally the high quality marine engineering technical personnel with innovation ability and adaptive to socialist economic development of china can be trained.
\end{abstract}

\section{Introduction}

"Who controls the ocean, who controls everything", 500 BC, the wisdom of ancient Greece famous thinker, oceanographer Dimitry Stoker. And in the new era of developing and exploiting Deep Ocean, it is still ringing in our ears ${ }^{[1]}$. The national strategy of "going to the sea" is a common experience for the success of the marine power and the region. In 2012, the major reports of the Eighteenth National Congress of the CPC build marine power to the height of the national development strategy for the first time, specific put forward" improve the efficiency of marine resources development, protect the marine environment, resolutely safeguard national maritime rights and interests and build China into a maritime power", develop the strategic vision of the marine economy. At the same time, in the seven country determined strategic emerging industries, four major emerging industries special planning has been completed, clearly pointed out accelerate the development of marine engineering equipment and materials.

However, development needs talent, but the urgent needs and training of our country's skilled personnel in the field of marine engineering equipment is facing a huge challenge. The "excellent engineer education and training program" (hereinafter referred to as " excellent plan ") pointed out the direction for the revitalization of the National Engineering Education, which was proposed by department of education as a reform pilot project. It aims to cultivate a large number of high-quality engineering and technical personnel with the ability innovation, adapt to the needs of economic and social development ${ }^{[2]}$.

Zhejiang province is a big marine economy province in China, the output value of marine economy was higher than other adjacent coastal provinces especially in 2011, but the lack of talent was leading to stagnation of marine machinery development in Zhejiang Province and even the whole of China, so seek the training strategy of marine machinery talent have the important practical significance. Hangzhou Dianzi University carrying the "marine electrical and mechanical equipment technology" key discipline of Zhejiang Province and built a "ship's port machinery and equipment technology" key laboratory. At the same time, as the first selected of the Excellent program pilot universities, Hangzhou Dianzi University has been working in the exploration and practice of cultivate innovative engineering talents teaching model by school enterprise cooperation, and the mechanical profession is first implemented as a pilot professional Excellent program. In order to promote implementation of the school enterprise cooperative talent fostering Excellent plan, we must enhance their enthusiasm to participate in school enterprise cooperation, then establishing a set of feasible school-enterprise cooperation excellent mechanical engineer sustainable 
development training strategy.

\section{Status and Problems}

(1) Marine Machinery Development

The ocean is the headstream of human civilization, World power in human history have been a maritime power."Maritime power" refers to near the ocean country have healthy marine ecosystem, the sustainable development of marine resources and the environment, marine science and technology advanced, well-developed marine economy, a strong ability to control the integrated management of maritime affairs, ocean powerful military strength ${ }^{[3]}$. China is a maritime country, Mechanical preparation on the ocean also belong to a maritime power, However, marine equipment development started late, ocean development lags behind; marine science and technology capability of independent innovation is weak. Marine industrial is relatively simple and so led to the existing problems in our country is not a maritime power.

We must clearly recognize that compared with developed countries, China's overall level of marine science and technology is a large gap. the countries have developed a range of marine policy from the fifties, but at the national level for coordination of marine science and technology management and long-term planning was nearly two years to do. Because of Marine scientific and technological backwardness, our oil and gas exploration, resource exploration, deep sea ocean shipping and others in a passive situation. Marine development strategy has brought important strategic opportunities and challenges for training of professional personnel.

(2) school-enterprise cooperation personnel training with excellent plan

To conduct the ocean strategy of China well, a plan for Educating and Training Excellent Engineer has been put into practice, which will provide a large amount of high quality marine engineering technical personnel with innovation ability and adaptive to socialist economic development of china. This plan must be conducted under the following principles: industry guidelines, university-enterprise cooperation, classifying implementation and multitudinousness. With excellent plan, a breakthrough of the training of engineers is strongly expected. Currently, this plan has only been conducted in a very short time, and the research about how to carry out the university-enterprise cooperation under the excellent plan is still at a preliminary stage. Presently, the university shows a much more enthusiasm than the enterprise about training engineers under this plan. Based on this problem, a complete and feasible plan for the cooperation of university and enterprise to conduct this training plan is becoming an urgent matter of the government.

In recent years, the Excellent program has been conducted in Hangzhou dianzi University. Yet a lot of problems happened has restricted the development of the cooperation of university and enterprise. How to find the common interests of university and enterprise and a way to get the win-win situation, balance the interests of each other, push the motivation of enterprise to cooperate with university, and improve the effect of excellent plan is a serious problem every university of engineering needs to think about carefully. In a word, the strategy of conducting the engineer training plan with the cooperation between the university and enterprise need to be optimized immediately.

\section{Sustainable methods of implementation of school-enterprise cooperation personnel training with excellent plan}

At present, the research on school-enterprise cooperation in excellent plan or at the background of excellent plan is still in its initial stage, for the excellent plan is not very long in our country. Diversified training model is to explore the new form of personnel training with the cooperation between colleges and industries or enterprises, and develop school-enterprise cooperation in various forms and channels. The successful implementation of the excellent plan must be closely related to the industries and enterprises, for the purpose of achieving the long-term cooperation of the current school-enterprise cooperation personnel training ${ }^{[4][5]}$. The concrete implementation strategies:

(1) Find the key problems existed in the excellent mechanical engineers training with the 
cooperation of current school and enterprise, and organize the commonness and reasons of these problems.

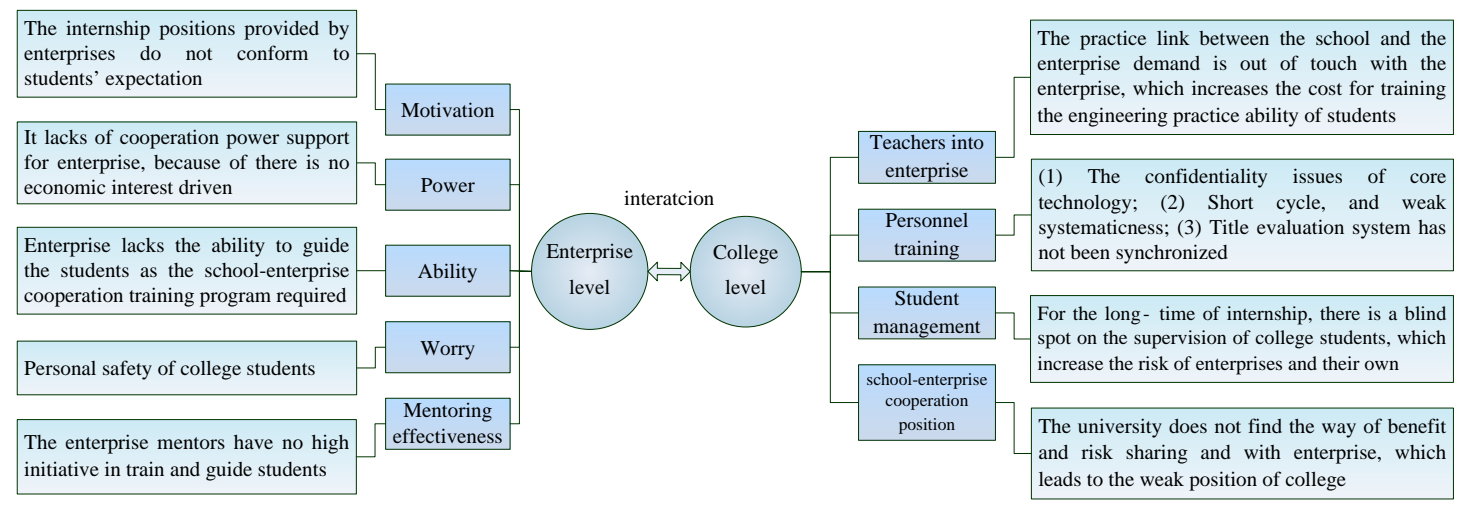

Fig.1 Existed problem and reason analysis of the school-enterprise cooperation

(2)Taking university-enterprise cooperation as the motivation of talent development, or in other words, we should find the way that how the universities dock with the enterprise benefits from the perspective of market-oriented development, and improve the initiatives and effectiveness of which the enterprises cooperate with universities.

Lacking of motivation is the most important reason why the effectiveness of university-enterprise cooperation is bad in the conduct of Excellent Plan. It is operable and effective for university-enterprise, to find the common interest and cooperation, only based on the economic interests of the enterprise and the cultural development requirements.

Firstly, with enterprises facing new challenges, many are struggling to determine how best to develop their talent to meet new and changing organizational needs. It is convenient for enterprises to get the right talents if they participate in formulating personnel training program. The mostly of enterprises need to train the new employees, it will spend too much time and cost much manpower and resources. On the contrary, enterprises can reduce much training costs if they recruit graduates who have finished internship.

Secondly, the existence and development of the modernized enterprise need the technology. In order to create a more powerful industry competitiveness, enterprises must improve the existing technology. Universities are cradle of advanced technology, they also need rely on the research of high-tech products to promote the development of themselves, so there is a natural suitability about technology between university and enterprise.

Thirdly, enterprises need social profiles and cultural image. In the situation of marketing economy, more and more enterprises begin to pay much more attention to building organization identity and corporate brands. It is better for enterprises to choice cooperation with universities, because enterprises not only can promote the social position and profile, but also can promote the influence and image in the mind of government and public.

It is not hard to find that the motivation of cooperation between enterprises and universities will be increased significantly if universities satisfy the needs of enterprises about talent, technology and profile. University-enterprise cooperation provides a stable platform to the training of excellent engineers. The training ways as follows:
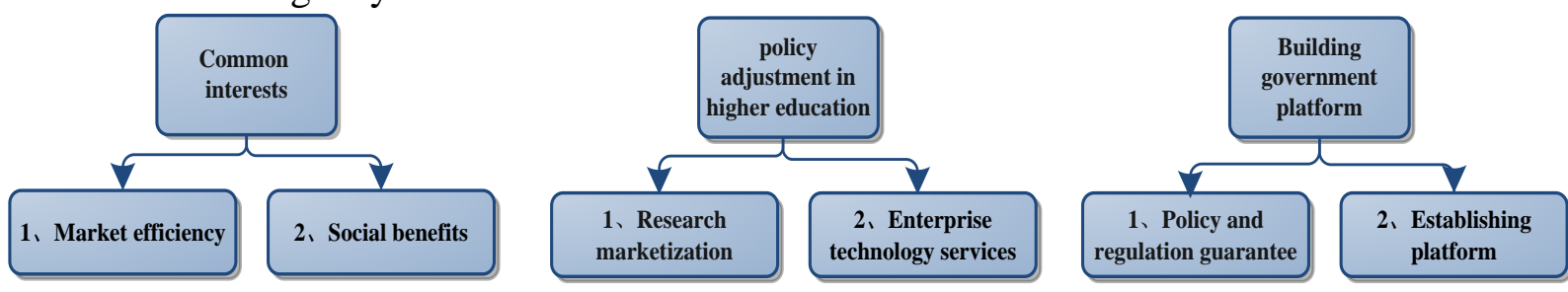

Fig. 2. The training ways of school-enterprise cooperation personnel training with excellent plan 


\section{Conclusion}

Around the new demand of national marine development strategy, with the intent to train excellence engineers and to find the common interest and cooperation, then improve the initiatives and effectiveness of which the enterprises cooperate with universities, establishing a set of feasible school-enterprise cooperation excellent mechanical engineer sustainable development training strategy. Finally the high quality marine engineering technical personnel with innovation ability and adaptive to socialist economic development of china can be trained.

\section{Acknowledgements}

The research is financially supported by the National Nature Science Foundation of China (No. 51505112), Nature Science Foundation of Zhejiang Province, China (No. LQ15E050010), Hangzhou Dianzi University higher education research project(No. YB201547).

\section{References}

[1] Jiang Zhaoxia, Marine Economy and the Coastal Economy of Jiangsu, J. Reformation \& Strategy, 2010, 12(26): 90-93.

[2] Zhang Daliang. Implementation of the "education plan" to accelerate the reform and development of Higher Engineering Education, J.Research on Higher Education in China, 2011,(1):16-19.

[3] ChenYinhui, The development strategy of the world's major marine power and Its Enlightenment to China, J. Chinese price, 2011.09:65-68.

[4] Huang Xiaotao, Wang Fen, Wu Chi, Focus on teaching process control to improve the quality of the training of excellent engineer, J. Chinese University Teaching, 2013,(9):30-32.

[5] John Heywood. Engineering Edueation:Researeh and Development in Cunreulum and Instruetion[M]. New Jesrey: John Wiley \& Sons,Inc,2005:134. 